\title{
Paternal hypoxia exposure primes offspring for increased hypoxia resistance
}

Alexandria Ragsdale ${ }^{15}$, Oscar Ortega-Recalde ${ }^{25}$, Ludovic Dutoit ${ }^{19}$, Anne A. Besson ${ }^{1}$, Jolyn H.Z. $\mathrm{Chia}^{1}$, Tania King ${ }^{1}$, Shinichi Nakagawa ${ }^{3}$, Anthony Hickey ${ }^{4}$, Neil J. Gemmell ${ }^{2}$, Timothy Hore ${ }^{2}$, Sheri L. Johnson ${ }^{* 1}$

${ }^{1}$ Department of Zoology, University of Otago, Dunedin, New Zealand

${ }^{2}$ Department of Anatomy, University of Otago, Dunedin, New Zealand

${ }^{3}$ Evolution and Ecology Research Centre, School of Biological, Earth and Environmental Sciences, University of New South Wales, Sydney, NSW, Australia

${ }^{4}$ School of Biological Sciences, University of Auckland, Auckland, New Zealand

*Corresponding author, sheri.johnson@otago.ac.nz

'These authors contributed equally to this work.

\section{ABSTRACT}

In a time of rapid environmental change, understanding how the challenges experienced by one generation can influence the fitness of future generations is critically needed. Using tolerance assays, transcriptomic and methylome approaches, we use zebrafish as a model to investigate transgenerational acclimation to hypoxia. We show that short-term paternal exposure to hypoxia endows offspring with greater tolerance to acute hypoxia. We detected two hemoglobin genes that are significantly upregulated by more than 7-fold in the offspring of hypoxia exposed males. Moreover, the offspring which maintained equilibrium the longest showed greatest upregulation in hemoglobin expression. We did not detect differential methylation at any of the differentially expressed genes, suggesting that another epigenetic mechanism is responsible for alterations in gene expression. Overall, our findings suggest that a 'memory' of past hypoxia exposure is maintained and that this environmentally induced information is transferred to subsequent generations, pre-acclimating progeny to cope with hypoxic conditions. 


\section{INTRODUCTION}

34 Paradigm-shifting research has revealed that the life-history experiences of parents can

35 influence the phenotype of their offspring through non-genetic mechanisms (Salinas et al., 2013;

36 Bohacek and Mansuy, 2015; O’Dea et al., 2016; Dias and Ressler, 2013; Gapp et al., 2014;

37 Radford et al., 2014; Burton and Metcalfe, 2014; Bonduriansky, 2012; Bonduriansky and Day,

38 2008). Non-genetically transmitted phenotypes can be generated by diverse environmental

39 effects, affecting a wide array of offspring traits, both positively and negatively (O'Dea et al.,

40 2016). Work on mice has demonstrated that learned fear responses (Dias and Ressler, 2013;

41 Gapp et al., 2014) and metabolic alterations associated with undernourishment can be inherited

42 via sperm (Radford et al., 2014). These studies suggest that parents can transmit information that

43 may benefit offspring survival. Through this transgenerational plasticity (also known as

44 transgenerational acclimation (Herman and Sultan, 2011; Marshall, 2008)), parents may provide

45 offspring with increased tolerance to environmental perturbations, such as contaminants (Araujo

46 et al., 2019; Kishimoto et al., 2017; Marshall, 2008), food shortages (Kishimoto et al., 2017;

47 Weyrich et al., 2018), carbon dioxide (Allan et al., 2014; Shi et al., 2020; Lee et al., 2020),

48 hypoxia (Ho and Burggren, 2012), but see (Truebano et al., 2018), salinity (Heckwolf et al.,

49 2020, 2018), and temperature (Donelson et al., 2014, 2012; Veilleux et al., 2015; Salinas and

50 Munch, 2012; Weyrich et al., 2018; Ryu et al., 2018). Studies have tended to focus on maternal

51 transgenerational plasticity, or have exposed both parents to the environmental perturbation,

52 making it impossible to disentangle the relative roles of mothers and fathers in altering offspring

53 phenotype (Guillaume et al., 2016; Rutkowska et al., 2020). Thus, a better understanding of the

54 specific role of paternal effects in transgenerational plasticity is needed, especially considering

55 environmental specific information is likely transferred via sperm (see below). Further, the 
underlying molecular processes have been identified in a just a few studies (Heckwolf et al., 2020; Kishimoto et al., 2017; Ryu et al., 2018; Shi et al., 2020; Strader et al., 2019; Veilleux et al., 2015). For example, metabolic genes are upregulated transgenerationally in the damselfish (Acanthochromis polyacanthus), suggesting shifts in energy production for maintaining performance at elevated temperatures (Veilleux et al., 2015). Potential epigenetic mechanisms

61 for this transgenerational acclimation have been detected, via differential methylation of genes

62 involved in energy homeostasis, mitochondrial activity, and oxygen consumption (Ryu et al.,

63 2018). In a time of rapid environmental change, a better understanding of how environmental

64 challenges experienced by organisms could increase the fitness of future generations to survive these same stressors is critically needed.

Hypoxia, defined as sufficiently low levels of oxygen to deprive tissues of oxygen, is a major physiological challenge (Diaz and Rosenberg, 2008; Long et al., 2015; Wang et al., 2016).

68 The aerobic lifestyle of most animals requires a constant supply of sufficient oxygen, and low oxygen levels constitute a major environmental threat (Roesner et al., 2006). Hypoxic conditions

70 precipitate conserved physiological effects in a wide array of vertebrates (Okumura et al., 2003;

71 Saxena, 1995; Wu et al., 2003), but hypoxia is particularly well-studied in aquatic species. The

72 total oxygen present in water at $30^{\circ} \mathrm{C}$ is only $0.5 \%$ that of air; hence, physiological stress of

73 hypoxia challenges many freshwater and marine organisms, and hypoxia is one of the most

74 widespread issues in aquatic habitats due to the rise of dead zones and climate change (Diaz and

75 Rosenberg, 2008; Jenny et al., 2016). Thus, it is now more important than ever to understand

76 how different aquatic species will response to environmental hypoxia. 
transgenerational effects, whereby marine medaka fish (Oryzias melastigma) exposed to hypoxia

80 show reproductive impairments in F1 and F2 generations, suggesting that hypoxia might pose a

81 long-lasting threat to fish populations (Lai et al., 2019; Wang et al., 2016). But fishes, in

82 particular, are also notable for their adaptive abilities to acclimate to hypoxic conditions

83 (Alexander et al., 2017; Diaz and Rosenberg, 2008; Nikinmaa, 2002; Richards, 2011), including

84 physiological, morphological, and phenotypic responses. Remarkably, goldfish (Carassius

85 auratus) and crucian carp (Carassius carassius) exhibit gill remodeling in response to hypoxia

86 exposure (Dhillon et al., 2013; Tzaneva et al., 2011). Zebrafish embryos and larvae modify

87 cardiac activity and blood vessel formation in response to hypoxic exposures (Pelster, 2002). In

88 addition to morphological alternations, gene expression can also be affected by hypoxic

89 conditions. In zebrafish gill tissue, more than 300 genes are differentially expressed between

90 hypoxia exposed individuals versus controls; these changes in gene expression are coupled with

91 morphological changes in gill structure, such as increased surface area of gill tissue (van der

92 Meer et al., 2005). Prolonged exposure to low oxygen has been shown to improve hypoxia

93 tolerance in Murray cod (Maccullochella peelii; (Gilmore et al., 2020) and snapper (Pagrus

94 auratus;(Cook et al., 2013)). Likewise, pre-acclimation of zebrafish larvae to mild hypoxia

95 significantly improves their resistance to lethal hypoxia, and upregulation of some oxygen

96 transport genes are associated with this acclimation (Long et al., 2015). Intriguingly, zebrafish

97 offspring of males and females exposed to chronic hypoxia have a higher resistance to acute

98 hypoxia than those of controls (Ho and Burggren, 2012), despite the offspring having never been

99 exposed to hypoxia, suggesting that parents may pass on information that may pre-acclimate

100 offspring to cope with hypoxic conditions. 
Gene expression and transgenerational effects can be regulated by epigenetic modifications, including DNA methylation, histone modifications, and non-coding microRNAs

103 (O'Dea et al., 2016). For example, in the marine medaka studies, transgenerational effects are

104 associated with differential methylation in sperm and ovary, with altered gene expression in

105 genes known to be associated with spermatogenesis and gene silencing (Wang et al., 2016) and

106 cell cycle control and cell apoptosis (Lai et al., 2019). DNA methylation has also been

107 investigated as a means underlying transgenerational effects of chemical exposures in zebrafish

108 (Carvan et al., 2017) and the paternal methylome is believed to be stably transmitted to offspring

109 in zebrafish (Jiang et al., 2013; Potok et al., 2013) without global reprogramming in primoridal

110 germ cells (Ortega-Recalde et al., 2019; Skvortsova et al., 2019), potentially facilitating

111 environmental specific information transfer.

112 Here we use zebrafish to further explore the phenomenon of transgenerational

113 acclimation of hypoxia in fishes. We focus on paternal exposure as we predict that

114 environmental specific information can be transferred via sperm, as observed in other studies

115 (Dias and Ressler, 2013; Lamb et al., 2020; Wang et al., 2016). We test whether paternal

116 exposure to hypoxia stimulates phenotypic responses in offspring, using behavioural

117 phenotyping to identify resistance to acute hypoxia (time to loss of equilibrium). We then use

118 RNA-Seq to identify candidate genes that are differentially expressed in control and hypoxic

119 progeny, and whole genome bisulfite sequencing data to assess whether changes in DNA

120 methylation underpin alterations in phenotype and gene expression (Figure 1). 


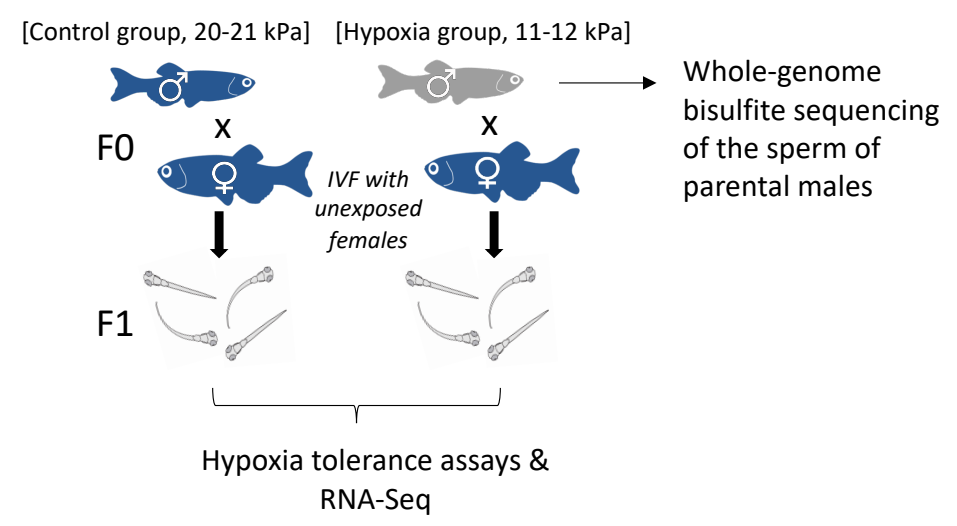

123 Figure 1. Experimental design. Groups of adult male zebrafish are maintained in normoxia (20$12421 \mathrm{kPa}, \mathrm{n}=20)$ or hypoxia $(11-12 \mathrm{kPa}, \mathrm{n}=20)$ for 14 days. Five males from each treatment were 125 then used to create F1 progeny, crossing the males to unexposed females ( $\mathrm{n}=5$ families/treatment), with half of the sperm used for whole genome bisulfite sequencing, to assess differential methylation ( $\mathrm{n}=3$ per treatment). At 20-21 days post fertilization, offspring undergo acute hypoxia tolerance (6-8 offspring/family) assays and $n=3$ offspring/treatment are used for differential gene expression analysis (RNA-Seq).

\section{MATERIALS AND METHODS}

\section{Fish husbandry}

Breeding and husbandry took place within the Otago Zebrafish Facility (OZF), a temperature-

137 controlled facility maintained at $25-27^{\circ} \mathrm{C}, \mathrm{pH} 7-7.8$ and conductivity $300-500 \mu \mathrm{S}$. Fish were

138 maintained in a Tecniplast re-circulating system (Tecniplast, Varese, Italy) under a 14:10

139 light:dark photoperiodic cycle, with 30 minutes of simulated dawn and dusk at the start and end

140 of each day. Acute hypoxia assays took place in the Zoology Department, where room

141 temperature was controlled at $25^{\circ} \mathrm{C}$, with a $13.5 \mathrm{hr}(0700-2030 \mathrm{hr})$ light cycle with $30 \mathrm{~min}$ of

142 simulated dawn and dusk. Zebrafish were fed twice daily with dry food (ZM000-400, size-

143 dependent) and once daily with live rotifer (Brachionus spp. days 5-10 post fertilisation) or

144 artemia (Artemia salina; days 10+ post fertilization). All animals were collected and maintained 
145 according to the standards of the Animal Ethics Committee for the University of Otago, New

146 Zealand (protocol no. AEC 44/16).

\section{Hypoxia exposure}

In November 2016, nine-month-old male zebrafish (AB wild-type; n=20/treatment) were

151 exposed to hypoxic conditions (10.91-12.33 $\left.\mathrm{kPa} \mathrm{pO}_{2}\right)$ or control conditions (20-21 $\left.\mathrm{kPa}\right)$, for two

152 weeks. Two glass tanks $(36 \times 29 \times 26.5 \mathrm{~cm})$ were separated into three zones $(12 \times 29 \mathrm{~cm})$, with 10

153 fish in each outer compartment and two fine bubble diffusers and a filter positioned in the middle

154 compartment. The oxygen concentration of the treatment tank was maintained by using an

155 OxyGuard Mini probe (OxyGuard International, Denmark) and oxygen controller (Model

156 PR5714, PR Electronics, Denmark) that were connected to nitrogen and air cylinders (BOC Gas

157 Supplies, Food Fresh grade). An on/off relay output from the controller actuated a solenoid-

158 controlled flow of compressed nitrogen or compressed air (BOC Gas Supplies, New Zealand), to

159 maintain the system at 53.1-60\% air saturation (= 10.91-12.33 kPa or 4.38-4.95 mg/L) level

160 (Cook et al., 2013). Normoxic conditions in the control tank (>95\% saturation) were maintained

161 by continually passing air through the bubble diffusers, connected to an air pump. The oxygen

162 concentration in the tanks was confirmed with a YSI 85 probe (YSI, Inc., Ohio, USA). Both

163 tanks were siphoned for waste and received $10 \%$ water changes every three days. Calibration of

164 the oxygen probe was checked daily and recalibrated as necessary.

168 Progeny from five families per treatment ( $\mathrm{n}=5$ hypoxia, $\mathrm{n}=5$ control) were generated by in vitro

169 fertilisation (IVF) (Johnson Sheri L. et al., 2018; Lamb et al., 2020) seven days after parental

170 exposure finished. Briefly, eggs and sperm were collected using abdominal massage - half the 
171 sperm was used for IVF and the other half was stored for subsequent DNA extraction. Offspring

172 were reared to $20-21 \mathrm{dpf}$ when $\mathrm{n}=8$ offspring per family (except family $\mathrm{C} 5$, where $\mathrm{n}=6$; total $\mathrm{n}$

$173=77)$ were challenged by acute hypoxia assays in small acrylic chambers $(100 \mathrm{~mm} \mathrm{H} \mathrm{x} 50 \mathrm{~mm} \times$

$17450 \mathrm{~mm}$ ). A 0-1 $\mathrm{kPa}$ oxygen level was achieved by continually passing compressed nitrogen

175 through a bubble diffuser for at least 10 minutes before assays and continuously passing the

176 nitrogen through a valve in the top of the chambers during the assay. The oxygen concentration

177 fluctuated between 0 and 1\%, monitored using a fibre-optic oxygen probe (Foxy OR-125)

178 attached to an Ocean Optics ${ }^{\circledR}$ USB 2000 spectrophotometer with USB-LS-450 light source and

179 the manufacturer's software (OOI Sensors). Each fish was filmed for 240 seconds and recorded

180 with a GoPro Hero 3+ camera. A total of 77 videos $(n=37$ control, $n=40$ hypoxia $)$ were tracked

181 using EthoVision XT behavioral tracking software, version 11.5 (Noldus Information

182 Technology, Netherlands). Fish were then immediately euthanized by submersion in ice and

183 stored in RNAlater (Invitrogen). One offspring from family C1 stayed at the bottom the entire

184 assay, so this individual was removed from further analyses.

185 Resistance to acute hypoxia, defined as the first time that progeny lost equilibrium for 3

186 seconds or more during hypoxia assays (Ho and Burggren, 2012), and the loss of equilibrium

187 frequency were analysed using R v.3.5.1 (R Core Team, 2018). Loss of equilibrium $>3 \mathrm{~s}$ was

188 initially modelled using a gaussian generalized linear model, and loss of equilibrium frequency

189 as a poisson generalized linear model, with treatment (control vs. hypoxia) as a fixed effect. To

190 account for multiple fry per family being tested, we also ran the models incorporating Treatment

191 ID as a random effect, using a gaussian linear model for time to loss of equilibrium $>3 \mathrm{~s}$ and a

192 poisson linear mixed effects model for the loss of equilibrium frequency. Significant

193 heterogeneity was obvious in the time to loss of equilibrium, so a linear mixed model 
194 incorporating heteroscedasity was compared to the model assuming homogeneity, by

195 incorporating the variance in Treatment into the model (Cleasby and Nakagawa, 2011).

\section{RNA-Seq library preparation and analysis}

Total RNA from six whole 20-21 dpf offspring (3 control offspring, 3 treatment offspring) was extracted using a Zymo Duet extraction kit (Zymo, NZ). The integrity of RNA samples was 201 determined using an Agilent RNA 6000 Nano chip on an Agilent 2100 Bioanalyzer to check that 202 the samples had an RNA Integrity Number (RIN) value of 8-9. Total RNA concentration was measured by Qubit 2.0 Fluorometer (Qubit RNA HS Assay Kit, Life Technologies). Samples

204 were sent to the Otago Genomics and Bioinformatics Facility at the University of Otago, under 205 contract to New Zealand Genomics Limited, for library construction and RNA sequencing. sample preparation kit (Illumina), as per the manufacturer's instructions. RNA sequencing was performed on the Illumina HiSeq2500 (Illumina, USA) machine with single-ended 100-bp reads generating 17.4-20.0 million reads per sample.

211 [https://www.bioinformatics.babraham.ac.uk/projects/trim_galore/] in a two-step process. First,

212 sequencing adaptors were removed, $10 \mathrm{bp}$ were hard-trimmed from the 5' end to account for

213 sequence bias produced by PBAT library preparation, and last, low-quality ends from reads

214 (PHRED score <20) were removed (Bolger et al., 2014). The reads were then aligned to the

215 zebrafish genome (GCRz11) using HISAT2 v2.2.0 (Kim et al., 2015), informed with the

216 GCRz11.99 annotation. Expression was summarized sample by sample at the gene level using 217 featureCounts v2.0.0 (Liao et al., 2014). The analysis of differential expression was conducted in 218 R v.3.5.0 (R Core Team, 2018) using the DESeq2 package v1.24.0 (Love et al., 2014) without 
219 the independent filtering option implemented in the results function (see

220 https://github.com/OscarOrt/Paternal_hypoxia_Ragsdale_2020). Differentially expressed genes

221 between offspring of fathers exposed to hypoxia and controls were extracted after correcting for

222 multiple testing using False Discovery Rate cut-off of q=0.05 (Benjamini and Hochberg, 1995a).

223 In order to test for over/under-representation of biological pathways which differentially

224 expressed genes are involved, enrichment of Gene Ontology (GO) analysis terms was performed 225 using Gorilla online accessed on August 42020 (Eden et al., 2009).

\section{Whole genome bisulfite sequencing and analysis}

228 DNA from six parental sperm samples was purified using a modified magnetic bead method

229 (Peat et al., 2017). WGBS was undertaken using an adapted modified post-bisulfite adaptor

230 tagging (PBAT) method (Miura et al., 2012; Peat et al., 2014). Briefly, bisulfite treatment was

231 performed according to the EZ Methylation Direct Mag Prep kit (Zymo, D5044) instruction

232 manual. Bisulfite treatment was performed before adaptor tagging, enabling simultaneous

233 conversion of unmethylated cytosines, DNA fragmentation, and improving library preparation

234 efficiency. Sequencing primers were added using random heptamer primers, and finally, sample-

235 specific indexes and sequences required for Illumina flow-cells binding were added by PCR.

236 Library integrity was assessed by agarose gel electrophoresis and a fragment analyser (Agilent)

237 and sequenced on eight lanes (one flow cell) of an Illumina HiSeq using HiSeq2500 V4

238 sequencing of 100 bp single ended reads (in combination with 13 other samples, which were part

239 of another study).

240 Raw reads were trimmed in Trim Galore v0.6.4 as previously mentioned. Read mapping

241 was performed using Bismark v0.22.3 (Krueger and Andrews, 2011) with the option --pbat 
242 specified. Zebrafish genome version 11 (GRCz11) was used as reference. BAM files were

243 deduplicated and reports containing methylation base calls were generated using the

244 deduplicate_bismark and bismark_methylation_extractor scripts, respectively. The non-

245 conversion rate during the bisulfite treatment was evaluated by calculating the proportion of non-

246 CG methylation; by this measure, all libraries must have had a bisulfite conversion efficiency of

247 at least $98.5 \%$ (Table S3).

248 CG methylation calls were analyzed in SeqMonk v1.47.0 [www.

249 bioinformatics.babraham.ac.uk/projects/seqmonk]. To analyse methylation at gene level, probes

250 with a minimum of 5 methylation calls were generated and the percentage methylation measured

251 as number of methylated calls/total calls. CpG islands (CGIs) were identified using Gardiner-

252 Garden \& Frommer's criteria and previously published datasets. For the former, 200-bp windows

253 moving at 1-bp intervals were considered CGIs if the Obs/Exp value was greater than 0.6 and a

254 GC content greater than 50\%. For the latter, data obtained by biotinylated CxxC affinity

255 purification (Bio-CAP) and massive parallel sequencing was used to identify non-methylated

256 CpG islands (Long et al., 2013).

Coupling between methylation and gene expression in differentially expressed genes

258 (DEG) and at genome level was interrogated using methylation levels at transcription start sites

259 (TSS). TSS were defined as $200 \mathrm{bp}$ centered on the first nucleotide of an annotated mRNA, and a

260 threshold of at least 20 methylation calls to be included in the analysis. DEG were divided into

261 underexpressed and overexpressed, whereas coupling at genome level was assessed dividing

262 gene expression levels into quartiles. Custom annotation tracks were generated using Gviz

263 v1.28.3 (Hahne and Ivanek, 2016). 


\section{RESULTS}

\section{Hypoxia tolerance assays in unexposed offspring}

268 Progeny of males exposed to moderate hypoxia for 14 days show a greater resistance to acute

269 hypoxia than progeny of control males - time to loss of equilibrium was, on average, 32 seconds

270 longer for progeny of hypoxia exposed males $(\mathrm{t}=2.52, \mathrm{p}=0.014$; confidence interval $(\mathrm{CI})=$

$2717.38,58.83$; Figure 2A) and the progeny of hypoxia exposed males lost equilibrium, on average,

2729.18 times vs. 12.32 times in the control progeny $(\mathrm{t}=-4.21, \mathrm{p}<0.0001, \mathrm{CI}=-0.433,-0.158$;

273 Figure 2B). However, when accounting for family (to avoid pseudo-replication due to multiple

274 offspring per family being tested), the effect of time to loss of equilibrium becomes non-

275 significant $(\mathrm{t}=1.67, \mathrm{p}=0.133, \mathrm{CI}=-12.66,79.22$; note this model accounts for observed

276 heterogeneity in the data), though the effect remains for the number of times offspring lost

277 equilibrium $(\mathrm{z}=-2.46, \mathrm{p}=0.014, \mathrm{CI}=-0.567,-0.037)$. Hence, there are strong family effects

278 (time to loss of equilibrium Treatment ID variance $=42.38$; loss of equilibrium frequency

279 Treatment ID variance $=0.025$ ), with greater resistance to acute hypoxia being observed for just

280 two families, $\mathrm{H} 1$ and $\mathrm{H} 2$ (Figure 2C and D). 

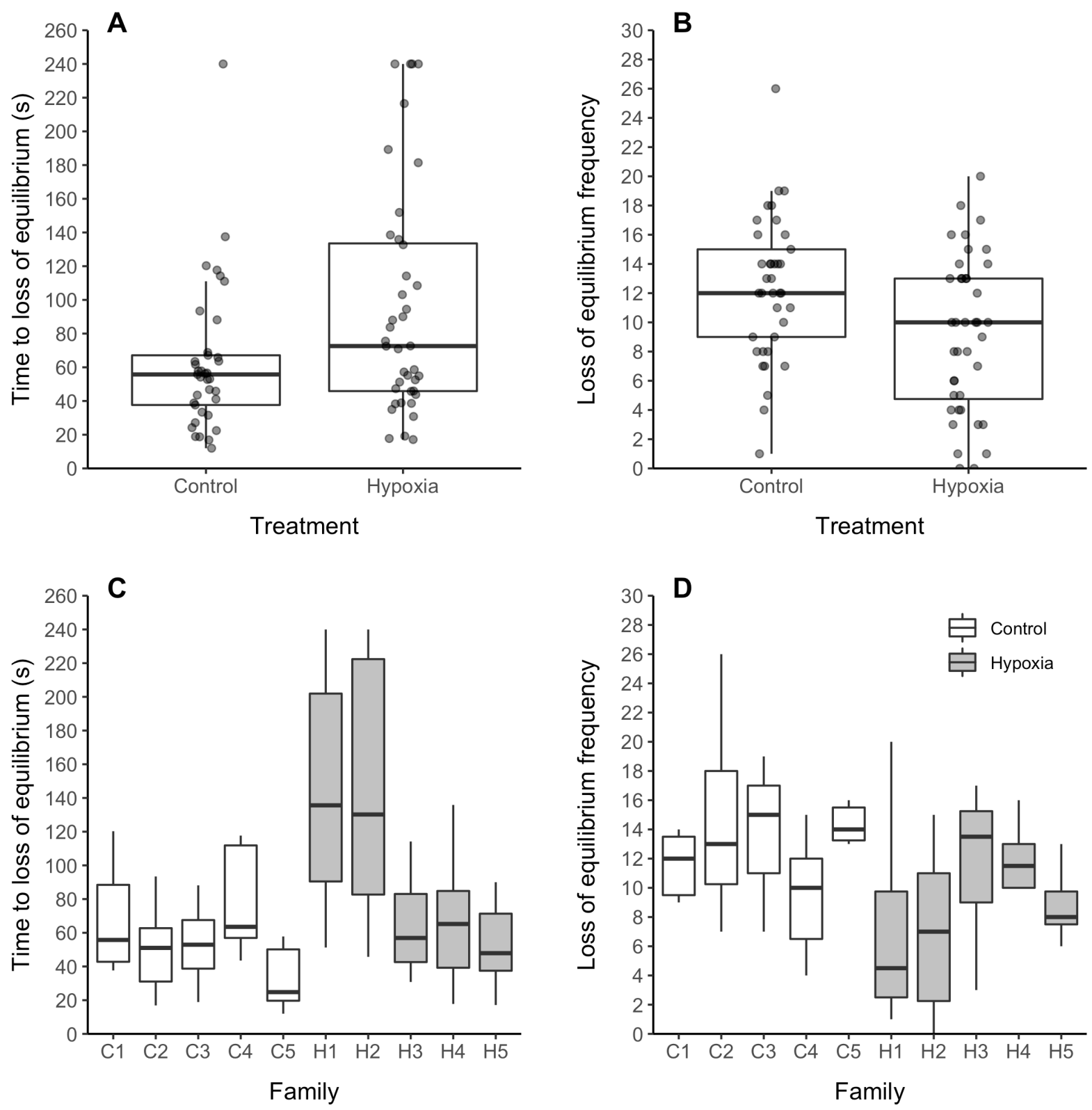

Figure 2. Hypoxia tolerance assays of unexposed offspring of control vs. hypoxia treated males. A and C) Time to first loss of equilibrium $>3 \mathrm{sec}, \mathrm{B}$ and D) loss of equilibrium frequency - panels $\mathrm{C}$ and $\mathrm{D}$ are broken down by family. $\mathrm{N}=6-8$ progeny/family x 5 families/treatment. Tolerance assays done at 20-21 days post fertilization, following 14 day parental exposures (20$21 \mathrm{kPa}$ normoxia control vs. 11-12 kPa hypoxia treatment). Boxes illustrate the interquartile range (medians, $25^{\text {th }}$ and $75^{\text {th }}$ percentiles), and whiskers illustrate $1.5^{*}$ the interquartile range, above and below the $75^{\text {th }}$ and $25^{\text {th }}$ percentiles. 


\section{Transcriptome wide gene expression patterns in unexposed offspring}

294 We sequenced 17.4 - 20.0 million reads per sample. Mapping assigned 14.1 - 16.1 million reads

295 to genes, representing $80.15-81.41 \%$ of reads uniquely assigned to a gene, with detected

296 expression in 26,260 of the 32,057 genes in the GRCz11.99 annotation.

A total of 91 genes were significantly differentially expressed between the offspring of

298 control and hypoxia exposed males (Figure 3; Table S1). Of the 91 differentially expressed

299 genes, 36 genes were significantly upregulated, and 55 were significantly downregulated in the

300 offspring of hypoxia exposed males (Figure 3). Eight genes exhibited greater than 4-fold change

301 in differential expression (2 upregulated in hypoxia, 6 downregulated in hypoxia) (Figure 4).

302 Most notably, two hemoglobin genes (hbaal and hbz (si:ch211-5k11.6); Figure 4 and 5A) were

303 upregulated by more than 12-fold in offspring of hypoxia exposed F0 males. Three additional

304 genes were upregulated by more than 7-fold, but did not pass False Discovery Rate (FDR)

305 correction - these included a third hemoglobin gene (hbbal; Figure 4 and 5A; Table S2) and a

306 major histocompatibility gene (mhclula; Figure 4). Importantly, the observed upregulation in

307 hemoglobin gene expression correlates with the differential family effects observed in our loss of

308 equilibrium tolerance assays (compare Figure 2 with Figure 5A/Table S2). Sequenced offspring

309 from the $\mathrm{H} 1$ and $\mathrm{H} 2$ families, the two families that show the greatest tolerance to acute hypoxia,

310 also show the greatest upregulation in gene expression. Indeed, the sequenced H1 offspring

311 never lost equilibrium within our 240s long assay and the sequenced H2 offspring first lost

312 equilibrium at 216.5 s, whereas the third hypoxia offspring, from family $\mathrm{H} 3$ (with a first loss of

313 equilibrium at 181.5s), and the offspring from $\mathrm{C} 1-\mathrm{C} 3$ (first loss of equilibrium $>3 \mathrm{~s}$ at 38.8, 24.2

314 and 18.9s, respectively) show little to no expression at these hemoglobin genes. 
316 males (Figure 4), including timm23b (translocase of inner mitochondrial membrane 23 homolog

$317 \mathrm{~b}$ (yeast)), acot21 (acyl-CoA thioesterase 21), znf1156 (zinc finger protein 1156), cyt1l (type I

318 cytokeratin), irgel (immunity-related GTP-ase), and zgc:158417.

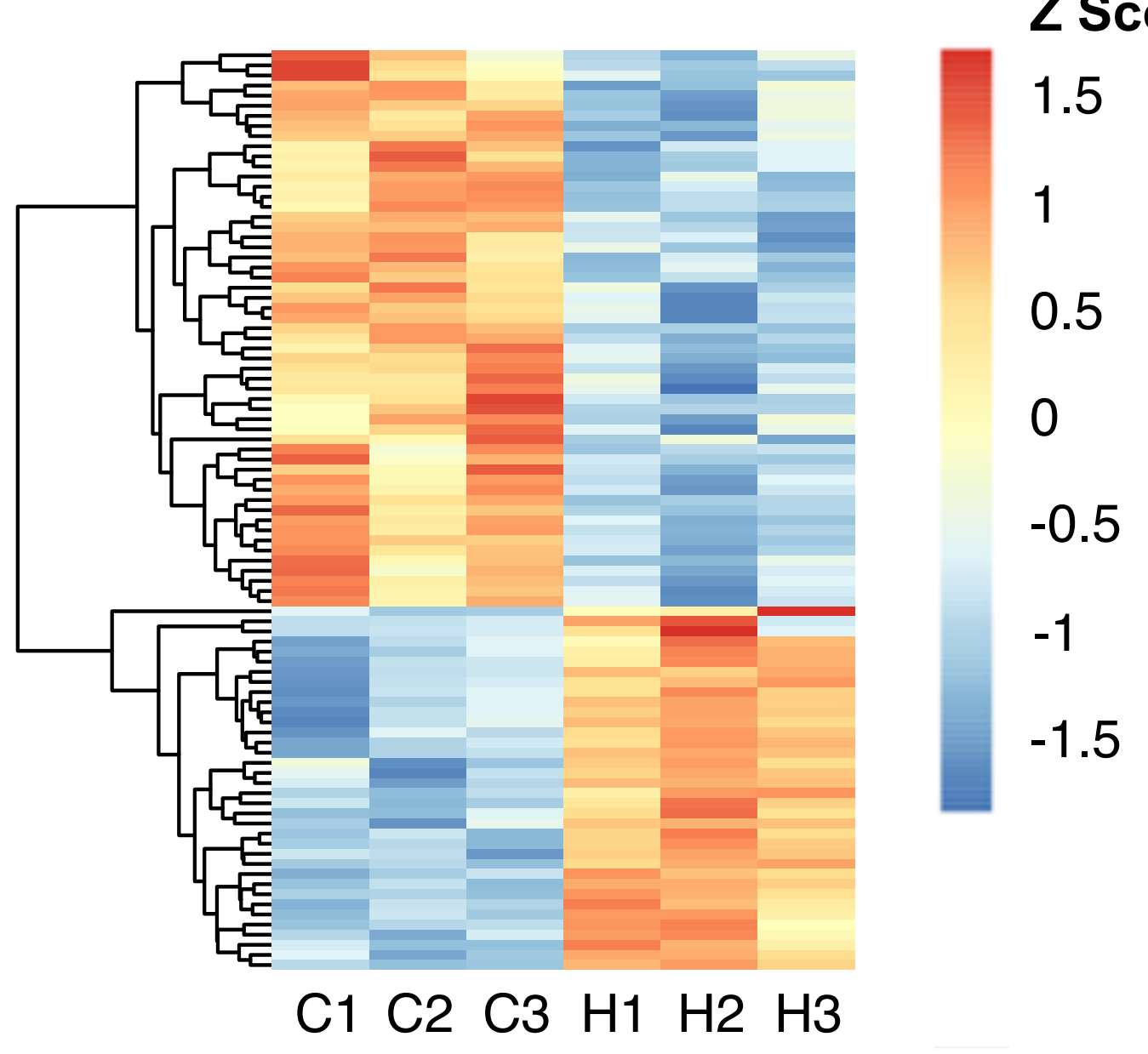

320 Figure 3. Differential gene expression in offspring of control vs. hypoxia treated males. 91

321 genes are differentially expressed between the 20-21 day old offspring of hypoxia $(n=3)$ and 322 control $(n=3)$ males, with an FDR $<0.05$. Red and blue colours represent higher and lower 323 expression, respectively. 
cyt11

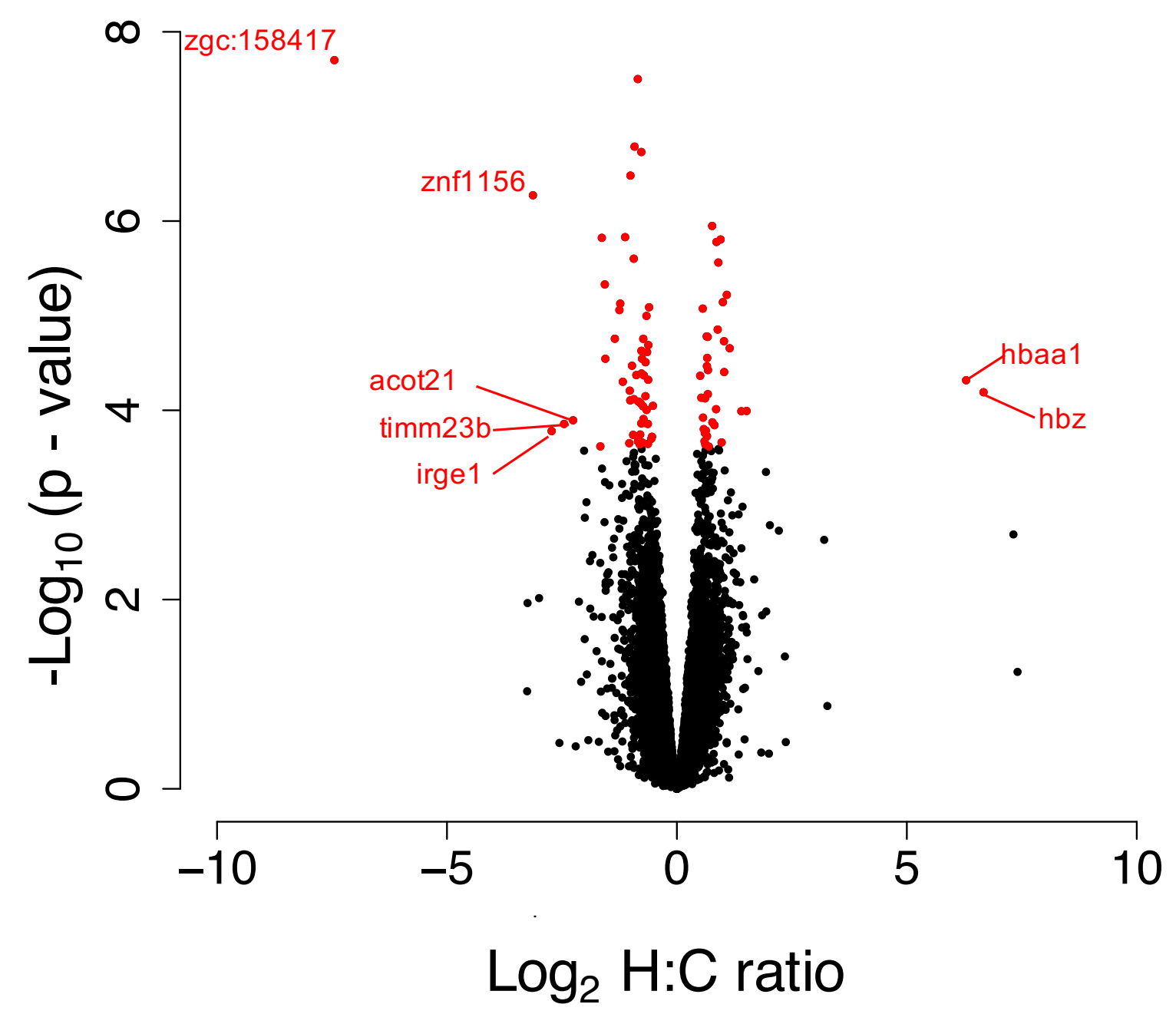

Figure 4. Volcano plot for differentially expressed genes in the offspring of control vs. hypoxia exposed males. 20-21 day old zebrafish F1 offspring from control $(n=3)$ and hypoxia $(\mathrm{n}=3)$ treated males, showing the distribution of significance $[-\log 10(\mathrm{p}-\mathrm{value})] v s$. fold change [ $\log 2$ (fold change)] for all genes. Each circle represents a gene, with significant genes (at 5\% FDR) highlighted in red. Genes with greater than 4-fold change in expression between control and hypoxia treatments are labelled.

Of the genes we analysed, 13,698 were associated with a GO term (including 58 of the 91 differentially expressed genes). Nine GO terms were overrepresented in our differentially 
expressed genes at a q-value cutoff of 0.1 (Table 1). Several significantly enriched GO terms were associated with lytic or proteolytic activity (i.e. serine hydrolase activity, serine-type endopeptidase activity, hydrolase activity, serine-type peptidase activity, glutamate

338 decarboxylase activity, endopeptidase activity, peptidase activity, peptidase activity, acting on L339 amino acid peptides). Proteolysis (GO:0006508 p-value $=7.43 \times 10^{-04} ; \mathrm{q}$-value $\left.=0.7640\right)$ tended

340 to be over-represented. Genes associated with the process of aging $(\mathrm{GO}: 0007568$; $\mathrm{p}$-value $=1.99$

$341 \times 10^{-05} ; \mathrm{q}$-value $\left.=0.1640\right)$ as well as to the response to oxidative stress (GO:0006979; p-value $=$

$3429.20 \times 10^{-04} ;$ q-value $\left.=0.841\right)$ also tended to be over-represented.

343

344

345

346

Table 1: Gene Ontology analysis terms associated with differentially expressed genes. Only terms with a False Discovery Rate q-value below 0.1 are displayed.

\begin{tabular}{|c|c|c|c|c|c|}
\hline GO term & $\begin{array}{l}\text { Sub- } \\
\text { ontology }\end{array}$ & Description & $\begin{array}{l}\text { Enrichmen } \\
\text { t factor }\end{array}$ & p-value & $\begin{array}{l}\text { FDR q- } \\
\text { value }\end{array}$ \\
\hline GO:0004252 & function & $\begin{array}{l}\text { serine-type } \\
\text { endopeptidase activity }\end{array}$ & 15.97 & $\begin{array}{l}2.47 \mathrm{x} \\
10^{-07}\end{array}$ & $7.55 \times 10^{-04}$ \\
\hline GO:0008236 & function & $\begin{array}{l}\text { serine-type peptidase } \\
\text { activity }\end{array}$ & 13.67 & $\begin{array}{l}7.18 \mathrm{x} \\
10^{-07}\end{array}$ & $1.10 \times 10^{-03}$ \\
\hline GO:0017171 & function & $\begin{array}{l}\text { serine hydrolase } \\
\text { activity }\end{array}$ & 13.67 & $\begin{array}{l}7.18 \mathrm{x} \\
10^{-07}\end{array}$ & $7.30 \times 10^{-04}$ \\
\hline GO:0016787 & function & hydrolase activity & 2.62 & $\begin{array}{l}1.56 \mathrm{x} \\
10^{-05}\end{array}$ & $1.19 \times 10^{-02}$ \\
\hline GO:0004351 & function & $\begin{array}{l}\text { glutamate } \\
\text { decarboxylase activity }\end{array}$ & 216.71 & $\begin{array}{l}2.09 \mathrm{x} \\
10^{-05}\end{array}$ & $1.28 \times 10^{-02}$ \\
\hline GO:0004175 & function & endopeptidase activity & 6.35 & $\begin{array}{l}3.34 \mathrm{x} \\
10^{-05}\end{array}$ & $1.70 \times 10^{-02}$ \\
\hline GO:0070011 & function & $\begin{array}{l}\text { peptidase activity, } \\
\text { acting on L-amino acid } \\
\text { peptides }\end{array}$ & 4.84 & $\begin{array}{l}8.66 x \\
10^{-05}\end{array}$ & $3.77 \times 10^{-02}$ \\
\hline GO:0008233 & function & peptidase activity & 4.64 & $\begin{array}{l}1.19 \mathrm{x} \\
10^{-04}\end{array}$ & $4.53 \times 10^{-02}$ \\
\hline GO:0009449 & process & $\begin{array}{l}\text { gamma-aminobutyric } \\
\text { acid biosynthetic } \\
\text { process }\end{array}$ & 216.71 & $\begin{array}{l}2.09 \mathrm{x} \\
10^{-05}\end{array}$ & $1.28 \times 10^{-02}$ \\
\hline
\end{tabular}


Global methylation changes in the sperm of parental males and the relationship between methylation in parental sperm and gene expression in offspring

To explore potential mechanistic explanations underlying increased tolerance to acute hypoxia and differential gene expression in the zebrafish offspring, we conducted whole genome bisulfite sequencing (WGBS) of sperm from hypoxic $(n=3)$ and control males $(n=3)$. We obtained an average of $67,891,334$ reads per methylome $(\mathrm{SEM} \pm 2,551,964)$ and a mapping efficiency of 45.02\% (SEM $\pm 0.07 \%)$. Global cytosine-guanine $(\mathrm{CG})$ dinucleotide methylation levels showed no differences between hypoxia and control samples $(84.15 \%$ and $84.23 \%$, respectively; $p>$ $0.05)$.

In jawed vertebrates, methylation of transcription start sites (TSS), and in particular regions enriched on CG dinucleotides (CGIs), is associated with transcriptional silencing (Peat et al., 2014). For two example cases, the upregulated hemoglobin cluster and the downregulated acot 21 gene, we characterized methylation at individual positions and CGI using statistical and experimental criteria (Gardiner-Garden and Frommer, 1987; Long et al., 2013). No differences in methylation levels were observed for these genes (Figure 5A). Next, we explored methylation

365 levels for all differentially expressed genes. Using a threshold of 20 methylation calls we

366 obtained 29 and 23 genes for the upregulated and downregulated groups. Whereas

367 downregulated genes are hypermethylated and upregulated genes are hypomethylated for

368 hypoxia and control samples, TSS methylation values remain stable when both groups of

369 samples are compared (Figure 5B). Finally, we explored the global effect of DNA methylation

370 on gene expression using expression quantiles. We found methylation levels in the parental

371 sperm and gene expression in the F1 offspring are coupled in hypoxia and control samples

372 (Figure 5C). 
bioRxiv preprint doi: https://doi.org/10.1101/2020.12.09.416727; this version posted December 9, 2020. The copyright holder for this preprint (which was not certified by peer review) is the author/funder, who has granted bioRxiv a license to display the preprint in perpetuity. It is made available under aCC-BY-NC-ND 4.0 International license.

A
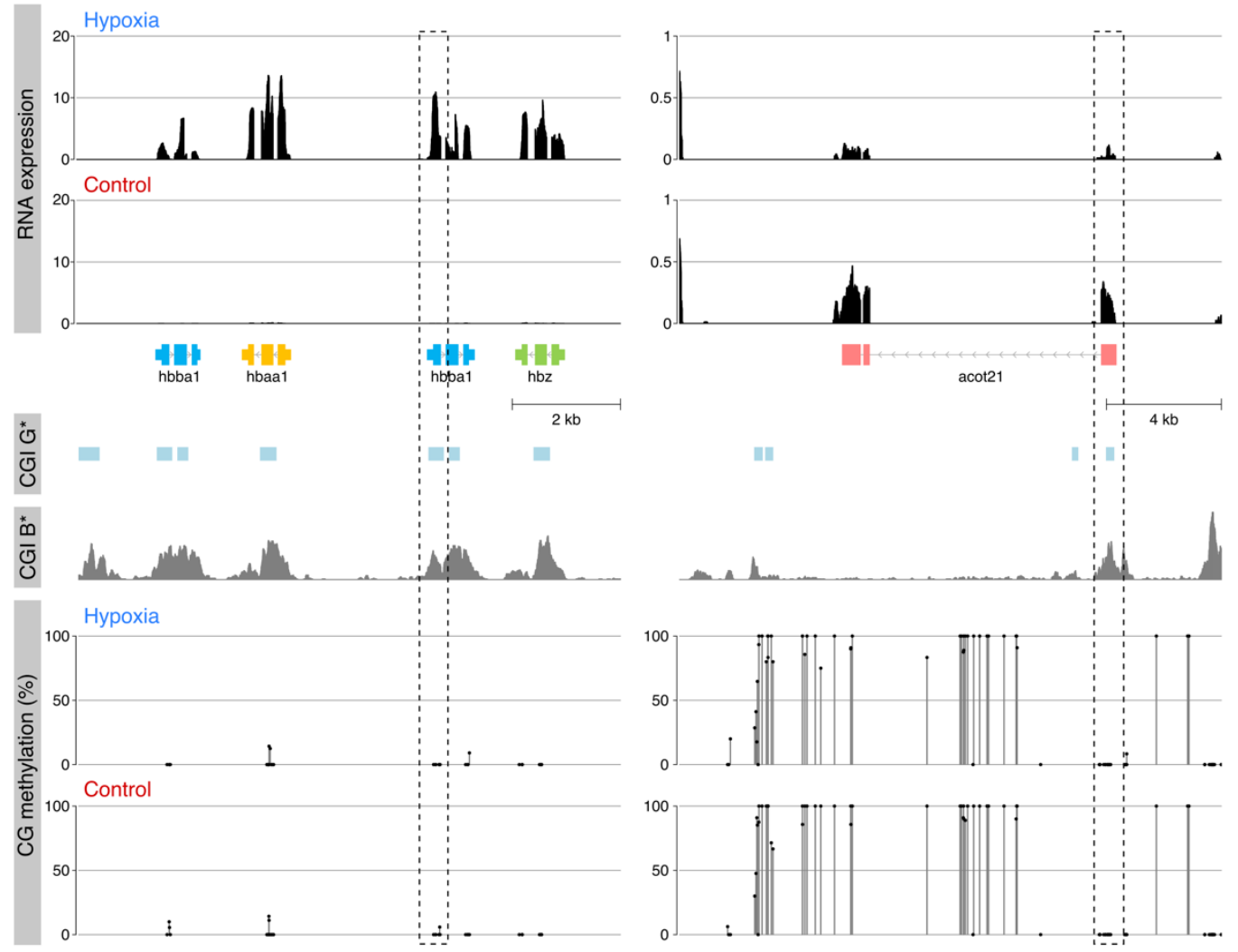

B
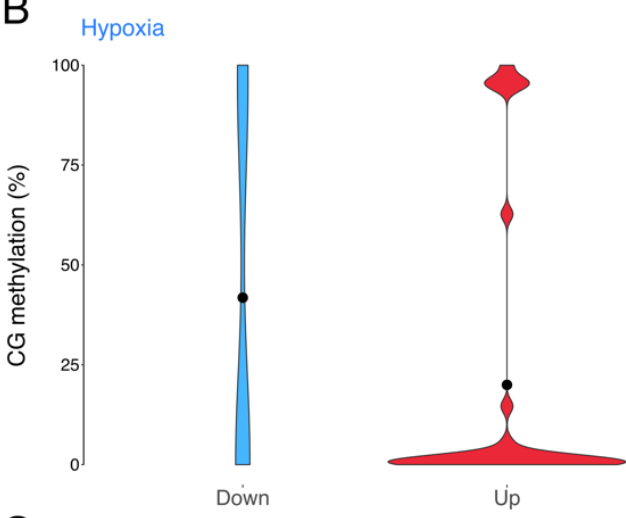

C

Hypoxia
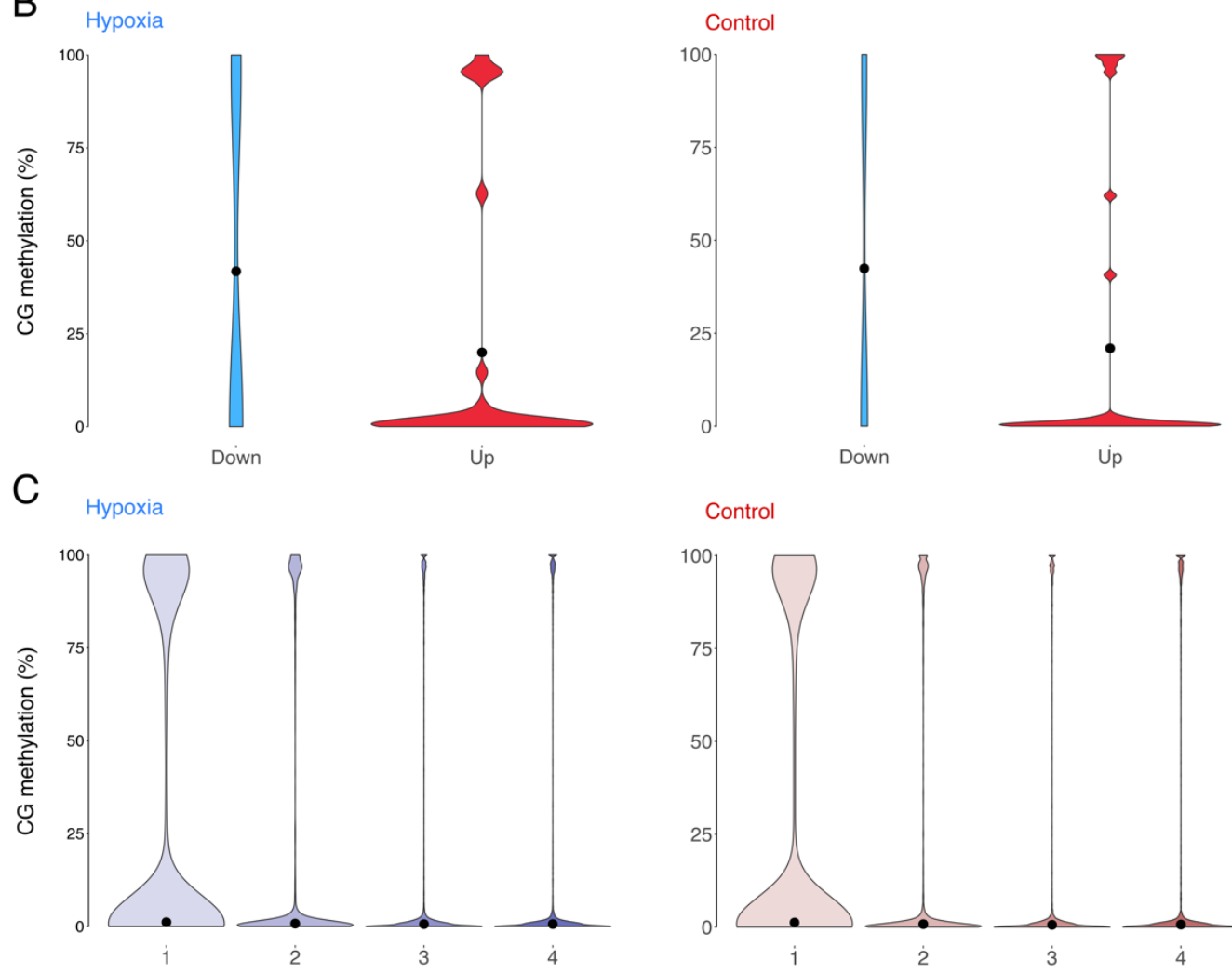

Up

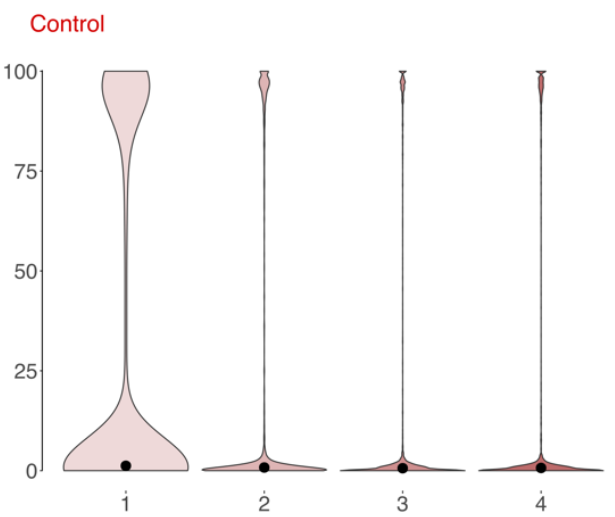


Figure 5. Global methylation changes and relationship between methylation in the sperm of hypoxia vs. control parental males and gene expression in the F1 progeny. A) Relationship between $\mathrm{CpG}$ methylation and RNA expression for $\mathrm{Hb}$ cluster and acot 21. CG methylation track shows methylation levels for dinucleotides with $>5$ calls; CGIs were predicted according to the Gardiner-Garden and Frommer criteria (CGI G*) and CxxC affinity purification (CGI B*). No changes in TSS methylation containing CGIs (dashed box) were observed for both genes (bottom). B) Violin plot showing distribution of methylation at transcription start sites (TSS) of differentially expressed genes in the F1 progeny. Downregulated genes are hypermethylated when compared to upregulated genes, however no clear differences were observed between both conditions. C) Violin plot showing distribution of methylation at TSS of genes classified into quartiles according to expression level (highest, 4). Each violin is scaled to the same maximum width (total area is not constant between violins) to demonstrate distributions for each quartile. Black dots denote the median.

\section{DISCUSSION}

We demonstrate that paternal exposure to hypoxia alters both the phenotypic response to hypoxia and gene expression in the offspring. Larvae of fathers that experienced moderate hypoxiamaintained equilibrium in acute hypoxia for longer than those of controls, indicating that paternal exposure stimulated a higher tolerance to hypoxic conditions. Using next-generation sequencing, we also detected significant changes in gene expression between control and hypoxia offspring, with two key hemoglobin genes upregulated in offspring of hypoxia exposed males -genes which may mediate the observed phenotypic differences, as they are involved in oxygen transport. This pattern of inheritance, through the paternal line, could have large evolutionary consequences as fathers are able to pass down valuable information to offspring that may enable better survival. However, the underlying mechanism for this transmission

401 remains unknown, as we did not detect any differential methylation in the sperm of parental

402 males at any of the differentially expressed genes. 
by ancestors can provide progeny with environmental specific information that might allow

406 future generations to survive the same environmental challenge, i.e., transgenerational plasticity

407 (Donelson et al., 2014, 2012; Heckwolf et al., 2018; Herman and Sultan, 2011; Lee et al., 2020;

408 Marshall, 2008; Ryu et al., 2018; Veilleux et al., 2015). In a previous study, 20 dpf larvae

409 exposed to $4 \mathrm{kPa} \mathrm{pO}_{2}$ revealed that offspring of parents exposed to hypoxia had longer time to

410 loss of equilibrium (hypoxia resistance; (Ho and Burggren, 2012)). In preliminary trials, we

411 found no behavioral differences using these oxygen parameters; thus, we increased the

412 magnitude of hypoxia, exposing larvae to $\sim 1 \mathrm{kPa}$, which produced the expected phenotypic

413 differences. Importantly, the previous study (Ho and Burggren, 2012) did not differentiate

414 between maternal and paternal effects and did not provide a possible mechanism underlying this

415 phenotypic effect.

It is important to note that our study detects intergenerational acclimation, with potential

417 for transgenerational acclimation. A transgenerational study requires rearing fish through to

418 create an F2 generation. Indeed, few studies that claim transgenerational acclimation are truly

419 transgenerational, as the studies are conducted across a single generation (O'Dea et al., 2016).

420 Even if parents are exposed to environmental challenges prior to maturity, the primordial germ

421 cells are still exposed to the challenge as well. Regardless, our results suggest that parents are

422 passing on information that may benefit offspring survival, thus facilitating acclimation to

423 environmental conditions.

$424 \quad$ To try and understand the underlying mechanism priming progeny to better cope with

425 hypoxic conditions, we conducted transcriptomic analysis of the progeny. We detected 91 genes

426 that were differentially expressed in the offspring of paternal males that were exposed to

427 moderate hypoxia for two-weeks. Most notably, two hemoglobin genes ( $h b a a l$ and $h b z$ ) 
exhibited over 7-fold differential expression, were upregulated in offspring of males exposed to hypoxia, with another hemoglobin gene, hbbal, also upregulated, though non-significantly. Remarkably, sequenced offspring from the $\mathrm{H} 1$ and $\mathrm{H} 2$ families, the two families that show the

431 greatest tolerance to acute hypoxia also show the greatest upregulation in hemoglobin gene

432 expression (Table S3). hbaal, hbz and hbbal are all found on chromosome 3, and are part of the 433 major hemoglobin locus responsible for heme binding, and are instrumental in oxygen transport 434 (Ganis et al., 2012). Exposing fish to hypoxia is typically considered to improve hypoxia 435 tolerance through alterations in hemoglobin, hemoglobin- $\mathrm{O}_{2}$ binding affinities, or cardiac 436 function to improve low $\mathrm{O}_{2}$ performance (Cook et al., 2013). Thus, differential expression of 437 hemoglobin genes (up-regulated in offspring from hypoxia exposed fathers) could indicate 438 altered physiological mechanisms to combat low oxygen, which could be precipitating the 439 increased tolerance to acute hypoxia in the $\mathrm{H} 1$ and $\mathrm{H} 2$ families.

440 The relationship between hypoxia and hemoglobin function has been studied in larval 441 zebrafish, suggesting that zebrafish larvae might be able to upregulate hemoglobin concentration 442 in response to chronic hypoxia (Schwerte et al., 2003). Under normoxic conditions, oxygen 443 supply via diffusion seems to be sufficient to meet metabolic demands up to 12-14 dpf in 444 zebrafish, but larvae appear to be able to use a circulatory system as a backup where necessary 445 (Schwerte et al., 2003). Further, impaired hemoglobin function does not impair routine oxygen 446 usage in normoxia or at moderate levels of hypoxia in 5-42 dpf larvae, but functional 447 hemoglobin does allow larvae to sequester extra oxygen from water in extreme hypoxic 448 conditions (Rombough and Drader, 2009). Larvae express embryonic/larval globins early in 449 development, but somewhere between days 16 and 22 the embryonic/larval globins begin to 450 decline (Ganis et al., 2012; Tiedke et al., 2011), and adult globin expression increases, with the 
451 adult globin expression pattern nearly completely established by day $32 \mathrm{dpf}$. hbae5

452 (ENSDARG00000045142) is the only embryonic/larval hemoglobin to show any pattern of

453 differential expression in our transcriptomic data. We found that this gene was highly expressed

454 and upregulated twice as much in our hypoxia offspring than in our control, though not

455 significantly differentiated after FDR correction $(\mathrm{p}=0.014, \mathrm{q}=0.391)$. hbae5 expression appears

456 to peak around $22 \mathrm{dpf}$ (Ganis et al., 2012), so upregulation of this gene should result in higher

457 affinity for oxygen, which may help explain the increased tolerance to the acute hypoxia that we

458 observed in our 20-21 dpf progeny. hbae5 has also been shown to be up-regulated more than 5-

459 fold by hypoxia in zebrafish larvae directly exposed to hypoxia; ((Long et al., 2015); note that

460 hbae5 is called hbz in their study).

461 In addition to two genes upregulated over 7-fold in offspring of hypoxia exposed males,

462 six genes were downregulated by more than 4-fold as well. These include timm23b (translocase

463 of inner mitochondrial membrane 23 homolog b (yeast)), an integral component of membranes.

464 Gene $\operatorname{acot} 21$ (acyl-CoA thioesterase 12), is a key component of acyl-CoA metabolic processes

465 with thiolester hydrolase activity and found in the cytoplasm. Gene znf1156 (zinc finger protein

466 1156) has metal ion binding functions. Gene zgc:158417 and irgel (immunity-related GTP-ase

467 family) are predicted to be integral component of membranes and used in GTP binding. Gene

468 cytll (type I cytokeratin) is predicted to have structural molecule activity. While there is little

469 information on these downregulated genes, expression changes of such significant magnitude are

$470 \quad$ likely to have large consequences.

An HRGFish database (Rashid et al., 2017) reports 50 key genes that are altered through

472 hypoxia, but we did not find any of them to be differentially expressed in our transcriptomic data

473 (Table S1, showing data for 46 of the 50 HRGFish genes referenced for the zebrafish), 
474 suggesting that the genes that are altered by direct exposure to hypoxia may be quite different to

475 those that may be passed on to future generations of hypoxia exposed ancestors. Importantly,

476 transcriptomic studies of F1 and F2 adult tissues, like heart, gill, brain and liver, might reveal

477 differential expression of some of these key hypoxia genes.

Interestingly, our GO analysis highlighted an overrepresentation of genes associated with

479 aging and oxidative stress. Studies have previously hypothesized a link between hypoxia (and

480 effects on respiration), oxidative stress (and free radical production) and aging in humans

481 (Katschinski, 2006; Valli et al., 2015), with several studies demonstrating age-related changes in 482 the hypoxia inducible factor system.

DNA methylation is known to be altered by hypoxia exposure in fishes (Lai et al., 2019;

484 Wang et al., 2016) and other vertebrates (Childebayeva et al., 2019; Zhang et al., 2017). Thus,

485 we hypothesized that hypoxia might produce changes in the paternal methylome, which are

486 inherited to the offspring, explaining the observed tolerance to acute hypoxia and differential

487 gene expression. Interesting, we found methylation levels and gene expression were coupled in

488 our hypoxia and control samples, despite the different tissues of origin for the methylome and

489 RNA expression data. This coupling supports a common pattern between the paternal methylome

490 and expression levels of the embryo. Yet, we observed no differences in methylation levels in

491 any differentially expressed genes, including the hemoglobin cluster, suggesting that sperm

492 methylation patterns are not responsible for changes in the observed changes in gene expression

493 in our study, or perhaps through epigenetic control away from the focal genes. The medaka

494 studies (Lai et al., 2019; Wang et al., 2016) exposed fish to a similar level of hypoxia, but for a

495 much longer period, the entire 3-month life cycle, which may explain why they observed

496 differential methylation in the sperm and we did not. If alterations to DNA methylation are not 
responsible for the changes in gene expression observed in our study, then perhaps histone modifications or miRNAs are at play. miRNA in medaka have also been identified as a potential underlying mechanism of transgenerational testis impairment induced by hypoxia by targeting genes associated with stress responses, cell cycle, epigenetic modifications, sugar metabolism, and cell motion (Tse et al., 2016).

In conclusion, our study demonstrates that paternal exposure to hypoxia is able to endow offspring with a higher resistance to hypoxic conditions and that upregulation of genes at the hemoglobin gene complex on chromosome 3 may explain these phenotypic effects. This study is the first to demonstrate that paternal exposure alone can mediate these changes in phenotype and gene expression. These findings suggest that paternal inheritance may be providing offspring with valuable environmental specific information (a 'memory') that could increase their survival, though it is unclear how this information is transmitted as we did not detect any differential methylation in the sperm of control and hypoxia treated males. Regardless, the variability in tolerance to acute hypoxia that we observed between hypoxia families suggests that progeny of

511 different genotypes respond to hypoxia in different ways, phenotypically (i.e., an epigenotype $\mathrm{x}$ environment interaction). In other words, environmental specific information is transferred through some genotypes, but not others, suggesting that pre-acclimation to hypoxic conditions may be driven by an interaction between the genotype, the epigenotype and the environment.

Acknowledgements. We thank Denham Cook for advice on designing our hypoxia system, Murray McKenzie for construction of the hypoxia system, and Sean Divers for help with set up and construction of the acute hypoxia assay chambers. Greg Gimenez provided advice on RNASeq analyses and Noel Jhinku and other members of the Otago Zebrafish Facility assisted with fish husbandry. Funding. This work was supported by a Royal Society of New Zealand Marsden Fund grant (UOO1507) and a University of Otago Research Grant to S.L.J. The funders had no role in study design, data collection and analysis, decision to publish, or preparation of 
J.C., and T.K. collected the data. A.R., S.L.J., O.O. and L.D. performed the analyses. A.R. and S.L.J led the writing of the manuscript, with assistance from O.O. and L.D. for bioinformatics aspects, and all the authors contributed to revisions. Competing interests. The authors declare no competing financial interests. Data and materials accessibility. The raw phenotypic data can be found at https://osf.io/xpy8j/. The accession number for the RNA-Seq and WGBS datasets reported in this paper is GEO:GSE160662. The source code for the bioinformatic analysis is publicly available on GitHub https://github.com/OscarOrt/Paternal hypoxia Ragsdale 2020.

\section{SUPPLEMENTARY MATERIALS}

535

Table S1. Results of differential gene expression analysis

Table S2. Read counts mapping to four hemoglobin genes

Table S3. Whole genome bisulfite sequencing summary data

\section{References.}

Alexander TJ, Vonlanthen P, Seehausen O. 2017. Does eutrophication-driven evolution change aquatic ecosystems? Philosophical Transactions of the Royal Society B: Biological Sciences 372:20160041. doi:10.1098/rstb.2016.0041

Allan BJM, Miller Gabrielle M., McCormick Mark I., Domenici Paolo, Munday Philip L. 2014. Parental effects improve escape performance of juvenile reef fish in a high-CO2 world. Proceedings of the Royal Society B: Biological Sciences 281:20132179. doi:10.1098/rspb.2013.2179

Araujo GS, Abessa DMS, Soares AMVM, Loureiro S. 2019. Multi-generational effects under single and pulse exposure scenarios in two monophyletic Daphnia species. Science of The Total Environment 697:134031. doi:10.1016/j.scitotenv.2019.134031

Benjamini Y, Hochberg Y. 1995a. Controlling the False Discovery Rate: A practical and powerful approach to multiple testing. Journal of the Royal Statistical Society Series B (Methodological) 57:289-300.

Benjamini Y, Hochberg Y. 1995b. Controlling the False Discovery Rate: A Practical and Powerful Approach to Multiple Testing. Journal of the Royal Statistical Society Series B (Methodological) 57:289-300.

Bohacek J, Mansuy IM. 2015. Molecular insights into transgenerational non-genetic inheritance of acquired behaviours. Nature Reviews Genetics 16:641.

Bolger AM, Lohse M, Usadel B. 2014. Trimmomatic: a flexible trimmer for Illumina sequence data. Bioinformatics 30:2114-2120. doi:10.1093/bioinformatics/btu170

Bonduriansky R. 2012. Rethinking heredity, again. Trends in Ecology \& Evolution 27:330-336. doi:10.1016/j.tree.2012.02.003

Bonduriansky R, Day T. 2008. Nongenetic Inheritance and Its Evolutionary Implications. Annu Rev Ecol Evol Syst 40:103-125. doi:10.1146/annurev.ecolsys.39.110707.173441

Burton T, Metcalfe NB. 2014. Can environmental conditions experienced in early life influence future generations? Proceedings of the Royal Society B: Biological Sciences 281:20140311. doi:10.1098/rspb.2014.0311

Carvan MJ III, Kalluvila TA, Klingler RH, Larson JK, Pickens M, Mora-Zamorano FX, Connaughton VP, Sadler-Riggleman I, Beck D, Skinner MK. 2017. Mercury-induced epigenetic transgenerational inheritance of abnormal neurobehavior is correlated with 
603

604

605

606

607

608

609

610

611

612

613

614

615

sperm epimutations in zebrafish. PLOS ONE 12:e176155. doi:10.1371/journal.pone.0176155

Childebayeva A, Harman T, Weinstein J, Goodrich JM, Dolinoy DC, Day TA, Bigham AW, Brutsaert TD. 2019. DNA Methylation Changes Are Associated With an Incremental Ascent to High Altitude. Frontiers in Genetics 10:1062. doi:10.3389/fgene.2019.01062 Cleasby IR, Nakagawa S. 2011. Neglected biological patterns in the residuals: A behavioural ecologist's guide to co-operating with heteroscedasticity. Behavioral Ecology and Sociobiology 65:2361-2372.

Cook DG, Iftikar FI, Baker DW, Hickey AJR, Herbert NA. 2013. Low-O2 acclimation shifts the hypoxia avoidance behaviour of snapper (Pagrus auratus) with only subtle changes in aerobic and anaerobic function. $J$ Exp Biol 216:369. doi:10.1242/jeb.073023

Dhillon RS, Yao L, Matey V, Chen B-J, Zhang A-J, Cao Z-D, Fu S-J, Brauner CJ, Wang YS, Richards JG. 2013. Interspecific differences in hypoxia-induced gill remodeling in carp. Physiological and Biochemical Zoology 86:727-739. doi:10.1086/673180

Dias BG, Ressler KJ. 2013. Parental olfactory experience influences behavior and neural structure in subsequent generations. Nature Neuroscience 17:89.

Diaz RJ, Rosenberg R. 2008. Spreading dead zones and consequences for marine ecosystems. Science 321:926. doi:10.1126/science.1156401

Donelson JM, McCormick MI, Booth DJ, Munday PL. 2014. Reproductive acclimation to increased water temperature in a tropical reef fish. PLOS ONE 9:e97223. doi:10.1371/journal.pone.0097223

Donelson JM, Munday PL, McCormick MI, Pitcher CR. 2012. Rapid transgenerational acclimation of a tropical reef fish to climate change. Nature Climate Change 2:30-32. doi:10.1038/nclimate1323

Eden E, Navon R, Steinfeld I, Lipson D, Yakhini Z. 2009. GOrilla: a tool for discovery and visualization of enriched GO terms in ranked gene lists. BMC Bioinformatics 10:48. doi:10.1186/1471-2105-10-48

Ganis JJ, Hsia N, Trompouki E, de Jong JLO, DiBiase A, Lambert JS, Jia Z, Sabo PJ, Weaver M, Sandstrom R, Stamatoyannopoulos JA, Zhou Y, Zon LI. 2012. Zebrafish globin switching occurs in two developmental stages and is controlled by the LCR. Developmental Biology 366:185-194. doi:10.1016/j.ydbio.2012.03.021

Gapp K, Jawaid A, Sarkies P, Bohacek J, Pelczar P, Prados J, Farinelli L, Miska E, Mansuy IM. 2014. Implication of sperm RNAs in transgenerational inheritance of the effects of early trauma in mice. Nature Neuroscience 17:667.

Gardiner-Garden M, Frommer M. 1987. CpG Islands in vertebrate genomes. Journal of Molecular Biology 196:261-282. doi:10.1016/0022-2836(87)90689-9

Gilmore KL, Doubleday ZA, Gillanders BM. 2020. Prolonged exposure to low oxygen improves hypoxia tolerance in a freshwater fish. Conservation Physiology 7. doi:10.1093/conphys/coz058

Guillaume AS, Monro K, Marshall DJ. 2016. Transgenerational plasticity and environmental stress: do paternal effects act as a conduit or a buffer? Functional Ecology 30:1175-1184. doi:10.1111/1365-2435.12604

Hahne F, Ivanek R. 2016. Visualizing Genomic Data Using Gviz and Bioconductor In: Mathé E, Davis S, editors. Statistical Genomics: Methods and Protocols. New York, NY: Springer New York. pp. 335-351. doi:10.1007/978-1-4939-3578-9_16 
Heckwolf MJ, Meyer BS, Döring T, Eizaguirre C, Reusch TBH. 2018. Transgenerational plasticity and selection shape the adaptive potential of sticklebacks to salinity change. Evolutionary Applications 11:1873-1885. doi:10.1111/eva.12688

Heckwolf MJ, Meyer BS, Häsler R, Höppner MP, Eizaguirre C, Reusch TBH. 2020. Two different epigenetic information channels in wild three-spined sticklebacks are involved in salinity adaptation. Sci $A d v$ 6:eaaz1138. doi:10.1126/sciadv.aaz1138

Herman J, Sultan S. 2011. Adaptive transgenerational plasticity in plants: case studies, mechanisms, and implications for natural populations. Frontiers in Plant Science 2:102. doi:10.3389/fpls.2011.00102

Ho DH, Burggren WW. 2012. Parental hypoxic exposure confers offspring hypoxia resistance in zebrafish (Danio rerio). J Exp Biol 215:4208. doi:10.1242/jeb.074781

Jenny J-P, Francus P, Normandeau A, Lapointe F, Perga M-E, Ojala A, Schimmelmann A, Zolitschka B. 2016. Global spread of hypoxia in freshwater ecosystems during the last three centuries is caused by rising local human pressure. Global Change Biology 22:1481-1489. doi:10.1111/gcb.13193

Jiang L, Zhang Jing, Wang J-J, Wang L, Zhang L, Li G, Yang X, Ma X, Sun X, Cai J, Zhang Jun, Huang X, Yu M, Wang X, Liu F, Wu C-I, He C, Zhang B, Ci W, Liu J. 2013. Sperm, but not oocyte, DNA methylome is inherited by zebrafish early embryos. Cell 153:773-784. doi:10.1016/j.cell.2013.04.041

Johnson Sheri L., Zellhuber-McMillan Sylvia, Gillum Joanne, Dunleavy Jessica, Evans Jonathan P., Nakagawa Shinichi, Gemmell Neil J. 2018. Evidence that fertility trades off with early offspring fitness as males age. Proceedings of the Royal Society B: Biological Sciences 285:20172174. doi:10.1098/rspb.2017.2174

Katschinski DM. 2006. Is there a molecular connection between hypoxia and aging? Experimental Gerontology 45:482-484. doi:doi:10.1016/j.exger.2005.12.003

Kim D, Langmead B, Salzberg SL. 2015. HISAT: a fast spliced aligner with low memory requirements. Nature Methods 12:357.

Kishimoto S, Uno M, Okabe E, Nono M, Nishida E. 2017. Environmental stresses induce transgenerationally inheritable survival advantages via germline-to-soma communication in Caenorhabditis elegans. Nature Communications 8:14031.

Krueger F, Andrews SR. 2011. Bismark: a flexible aligner and methylation caller for BisulfiteSeq applications. Bioinformatics 27:1571-1572. doi:10.1093/bioinformatics/btr167

Lai KP, Wang SY, Li JW, Tong Y, Chan TF, Jin N, Tse A, Zhang JW, Wan MT, Tam N, Au DWT, Lee B-Y, Lee J-S, Wong AST, Kong RYC, Wu RSS. 2019. Hypoxia causes transgenerational impairment of ovarian development and hatching success in fish. Environ Sci Technol 53:3917-3928. doi:10.1021/acs.est.8b07250

Lamb SD, Chia JHZ, Johnson SL. 2020. Paternal exposure to a common herbicide alters the behavior and serotonergic system of zebrafish offspring. PLOS ONE 15:e0228357. doi:10.1371/journal.pone.0228357

Lee YH, Jeong C-B, Wang M, Hagiwara A, Lee J-S. 2020. Transgenerational acclimation to changes in ocean acidification in marine invertebrates. Marine Pollution Bulletin 153:111006. doi:10.1016/j.marpolbul.2020.111006

Liao Y, Smyth GK, Shi W. 2014. featureCounts: an efficient general purpose program for assigning sequence reads to genomic features. Bioinformatics 30:923-930. doi:10.1093/bioinformatics/btt656 
661

662

663

664

665

666

667

668

669

670

671

672

673

674

675

676

677

678

679

680

681

682

683

684

685

686

687

688

689

690

691

692

693

694

695

696

697

698

699

700

701

702

703

704

705
Long HK, Sims D, Heger A, Blackledge NP, Kutter C, Wright ML, Grützner F, Odom DT, Patient R, Ponting CP, Klose RJ. 2013. Epigenetic conservation at gene regulatory elements revealed by non-methylated DNA profiling in seven vertebrates. eLife 2:e00348. doi:10.7554/eLife.00348

Long Y, Yan J, Song G, Li Xiaohui, Li Xixi, Li Q, Cui Z. 2015. Transcriptional events coregulated by hypoxia and cold stresses in zebrafish larvae. BMC Genomics 16:385. doi:10.1186/s12864-015-1560-y

Love MI, Huber W, Anders S. 2014. Moderated estimation of fold change and dispersion for RNA-seq data with DESeq2. Genome Biology 15. doi:10.1186/s13059-014-0550-8

Marshall DJ. 2008. Transgenerational plasticity in the sea: context-dependent maternal effects across the life history. Ecology 89:418-427. doi:10.1890/07-0449.1

Miura F, Enomoto Y, Dairiki R, Ito T. 2012. Amplification-free whole-genome bisulfite sequencing by post-bisulfite adaptor tagging. Nucleic Acids Research 40:e136-e136. doi:10.1093/nar/gks454

Nikinmaa M. 2002. Oxygen-dependent cellular functions - why fishes and their aquatic environment are a prime choice of study. Comparative Biochemistry and Physiology Part A: Molecular \& Integrative Physiology 133:1-16. doi:10.1016/S1095-6433(02)00132-0

O’Dea RE, Noble DWA, Johnson SL, Hesselson D, Nakagawa S. 2016. The role of non-genetic inheritance in evolutionary rescue: epigenetic buffering, heritable bet hedging and epigenetic traps. Environmental Epigenetics 2. doi:10.1093/eep/dvv014

Okumura A, Fuse H, Kawauchi Y, Mizuno I, Akashi T. 2003. Changes in male reproductive function after high altitude mountaineering. High Altitude Medicine \& Biology 4:349353. doi:10.1089/152702903769192304

Ortega-Recalde O, Day RC, Gemmell NJ, Hore TA. 2019. Zebrafish preserve global germline DNA methylation while sex-linked rDNA is amplified and demethylated during feminisation. Nature Communications 10:3053. doi:10.1038/s41467-019-10894-7

Peat J, Ortega-Recalde O, Kardailsky O, Hore T. 2017. The elephant shark methylome reveals conservation of epigenetic regulation across jawed vertebrates. F1000Research 6. doi:10.12688/f1000research.11281.1

Peat JR, Dean W, Clark SJ, Krueger F, Smallwood SA, Ficz G, Kim JK, Marioni JC, Hore TA, Reik W. 2014. Genome-wide bisulfite sequencing in zygotes identifies demethylation targets and maps the contribution of TET3 oxidation. Cell Reports 9:1990-2000. doi:10.1016/j.celrep.2014.11.034

Pelster B. 2002. Developmental plasticity in the cardiovascular system of fish, with special reference to the zebrafish. Comparative Biochemistry and Physiology Part A: Molecular \& Integrative Physiology 133:547-553. doi:10.1016/S1095-6433(02)00194-0

Potok ME, Nix DA, Parnell TJ, Cairns BR. 2013. Reprogramming the maternal zebrafish genome after fertilization to match the paternal methylation pattern. Cell 153:759-772. doi:10.1016/j.cell.2013.04.030

R Core Team. 2018. R: A Language and Environment for Statistical Computing. Vienna, Austria: R Foundation for Statistical Computing.

Radford EJ, Ito M, Shi H, Corish JA, Yamazawa K, Isganaitis E, Seisenberger S, Hore TA, Reik W, Erkek S, Peters AHFM, Patti M-E, Ferguson-Smith AC. 2014. In utero effects. In utero undernourishment perturbs the adult sperm methylome and intergenerational metabolism. Science 345:1255903-1255903. doi:10.1126/science. 1255903 
Rashid I, Nagpure NS, Srivastava P, Kumar R, Pathak AK, Singh M, Kushwaha B. 2017. HRGFish: A database of hypoxia responsive genes in fishes. Scientific Reports 7:42346.

Richards JG. 2011. Physiological, behavioral and biochemical adaptations of intertidal fishes to hypoxia. J Exp Biol 214:191. doi:10.1242/jeb.047951

Roesner A, Hankeln T, Burmester T. 2006. Hypoxia induces a complex response of globin expression in zebrafish (Danio rerio). J Exp Biol 209:2129. doi:10.1242/jeb.02243

Rombough P, Drader H. 2009. Hemoglobin enhances oxygen uptake in larval zebrafish (Danio rerio) but only under conditions of extreme hypoxia. J Exp Biol 212:778. doi:10.1242/jeb.026575

Rutkowska J, Lagisz M, Bonduriansky R, Nakagawa S. 2020. Mapping the past, present and future research landscape of paternal effects. BMC Biology 18:183. doi:10.1186/s12915020-00892-3

Ryu T, Veilleux HD, Donelson JM, Munday PL, Ravasi T. 2018. The epigenetic landscape of transgenerational acclimation to ocean warming. Nature Climate Change 8:504-509. doi:10.1038/s41558-018-0159-0

Salinas S, Brown SC, Mangel M, Munch S. 2013. Non-genetic inheritance and changing environments. Non-genetic Inheritance 38-50. doi:10.2478/ngi-2013-0005

Salinas S, Munch SB. 2012. Thermal legacies: transgenerational effects of temperature on growth in a vertebrate. Ecology Letters 15:159-163. doi:10.1111/j.14610248.2011.01721.x

Saxena DK. 1995. Effect of hypoxia by intermittent altitude exposure on semen characteristics and testicular morphology of male rhesus monkeys. International Journal of Biometeorology 38:137-140. doi:10.1007/BF01208490

Schwerte T, Überbacher D, Pelster B. 2003. Non-invasive imaging of blood cell concentration and blood distribution in zebrafish (Danio rerio) incubated in hypoxic conditions in vivo. J Exp Biol 206:1299. doi:10.1242/jeb.00249

Shi D, Zhao C, Chen Y, Ding J, Zhang L, Chang Y. 2020. Transcriptomes shed light on transgenerational and developmental effects of ocean warming on embryos of the sea urchin Strongylocentrotus intermedius. Scientific Reports 10:7931. doi:10.1038/s41598020-64872-X

Skvortsova K, Tarbashevich K, Stehling M, Lister R, Irimia M, Raz E, Bogdanovic O. 2019. Retention of paternal DNA methylome in the developing zebrafish germline. Nature Communications 10:3054. doi:10.1038/s41467-019-10895-6

Strader ME, Wong JM, Kozal LC, Leach TS, Hofmann GE. 2019. Parental environments alter DNA methylation in offspring of the purple sea urchin, Strongylocentrotus purpuratus. Journal of Experimental Marine Biology and Ecology 517:54-64. doi:10.1016/j.jembe.2019.03.002

Tiedke J, Gerlach F, Mitz SA, Hankeln T, Burmester T. 2011. Ontogeny of globin expression in zebrafish (Danio rerio). Journal of Comparative Physiology B 181:1011-1021. doi:10.1007/s00360-011-0588-9

Townhill BL, Pinnegar JK, Righton DA, Metcalfe JD. 2017. Fisheries, low oxygen and climate change: how much do we really know? Journal of Fish Biology 90:723-750. doi:10.1111/jfb.13203

Truebano M, Tills O, Collins M, Clarke C, Shipsides E, Wheatley C, Spicer JI. 2018. Short-term acclimation in adults does not predict offspring acclimation potential to hypoxia. Scientific Reports 8:3174. doi:10.1038/s41598-018-21490-y 
Tse AC-K, Li J-W, Wang SY, Chan T-F, Lai KP, Wu RS-S. 2016. Hypoxia alters testicular functions of marine medaka through microRNAs regulation. Aquatic Toxicology 180:266-273. doi:10.1016/j.aquatox.2016.10.007

Tzaneva V, Bailey S, Perry SF. 2011. The interactive effects of hypoxemia, hyperoxia, and temperature on the gill morphology of goldfish (Carassius auratus). American Journal of Physiology-Regulatory, Integrative and Comparative Physiology 300:R1344-R1351. doi:10.1152/ajpregu.00530.2010

Valli A, Harris AL, Kessler BM. 2015. Hypoxia metabolism in ageing. Aging (Albany NY) 7:465-466. doi:10.18632/aging.100782

van der Meer DLM, van den Thillart GEEJM, Witte F, de Bakker MAG, Besser J, Richardson MK, Spaink HP, Leito JTD, Bagowski CP. 2005. Gene expression profiling of the longterm adaptive response to hypoxia in the gills of adult zebrafish. American Journal of Physiology-Regulatory, Integrative and Comparative Physiology 289:R1512-R1519. doi:10.1152/ajpregu.00089.2005

Veilleux HD, Ryu T, Donelson JM, van Herwerden L, Seridi L, Ghosheh Y, Berumen ML, Leggat W, Ravasi T, Munday PL. 2015. Molecular processes of transgenerational acclimation to a warming ocean. Nature Climate Change 5:1074.

Wang SY, Lau K, Lai K-P, Zhang J-W, Tse AC-K, Li J-W, Tong Y, Chan T-F, Wong CK-C, Chiu JM-Y, Au DW-T, Wong AS-T, Kong RY-C, Wu RS-S. 2016. Hypoxia causes transgenerational impairments in reproduction of fish. Nature Communications 7:12114. doi: $10.1038 /$ ncomms 12114

Weyrich A, Lenz D, Fickel J. 2018. Environmental change-dependent inherited epigenetic response. Genes 10:4. doi:10.3390/genes10010004

Wu RSS. 2002. Hypoxia: from molecular responses to ecosystem responses. Marine Pollution Bulletin 45:35-45. doi:10.1016/S0025-326X(02)00061-9

Wu RSS, Zhou BS, Randall DJ, Woo NYS, Lam PKS. 2003. Aquatic hypoxia is an endocrine disruptor and impairs fish reproduction. Environ Sci Technol 37:1137-1141. doi:10.1021/es0258327

Zhang Yawen, Gou W, Ma J, Zhang Hongliang, Zhang Ying, Zhang Hao. 2017. Genome methylation and regulatory functions for hypoxic adaptation in Tibetan chicken embryos. PeerJ 5:e3891-e3891. doi:10.7717/peerj.3891 
bioRxiv preprint doi: https://doi.org/10.1101/2020.12.09.416727; this version posted December 9, 2020. The copyright holder for this preprint (which was not certified by peer review) is the author/funder, who has granted bioRxiv a license to display the preprint in perpetuity. It is made available under aCC-BY-NC-ND 4.0 International license.

\begin{tabular}{|c|c|c|}
\hline Gene_ID & log2FoldChange & pvalue \\
\hline ENSDARG00000101671 & -7.447901496 & $1.99 \mathrm{E}-08$ \\
\hline ENSDARG00000098800 & -3.130931401 & $5.34 \mathrm{E}-07$ \\
\hline ENSDARG00000014975 & -2.72345402 & 0.00016574 \\
\hline ENSDARG00000100375 & -2.453048439 & 0.00013931 \\
\hline ENSDARG00000036832 & -2.309127267 & $2.00 \mathrm{E}-09$ \\
\hline ENSDARG00000042513 & -2.257793529 & 0.0001275 \\
\hline ENSDARG00000104890 & -1.664931261 & 0.00024063 \\
\hline ENSDARG00000100504 & -1.63260871 & $1.50 \mathrm{E}-06$ \\
\hline ENSDARG00000088717 & -1.56758552 & 4.67E-06 \\
\hline ENSDARG00000041645 & -1.555587305 & $2.85 \mathrm{E}-05$ \\
\hline ENSDARG00000078878 & -1.349850562 & $1.75 \mathrm{E}-05$ \\
\hline ENSDARG00000059651 & -1.250202425 & $8.73 \mathrm{E}-06$ \\
\hline ENSDARG00000101479 & -1.232335842 & 7.45E-06 \\
\hline ENSDARG00000088625 & -1.176010143 & 4.99E-05 \\
\hline ENSDARG00000093193 & -1.126255412 & $1.48 \mathrm{E}-06$ \\
\hline ENSDARG00000075827 & -1.035496215 & 0.00022261 \\
\hline ENSDARG00000005179 & -1.024794268 & $6.21 \mathrm{E}-05$ \\
\hline ENSDARG00000090899 & -1.015231326 & $7.85 \mathrm{E}-05$ \\
\hline ENSDARG00000043729 & -1.010559912 & $3.31 \mathrm{E}-07$ \\
\hline ENSDARG00000074118 & -0.976528595 & $3.38 \mathrm{E}-05$ \\
\hline ENSDARG00000060350 & -0.951169523 & 0.00018177 \\
\hline ENSDARG00000079727 & -0.938155384 & $2.50 \mathrm{E}-06$ \\
\hline ENSDARG00000018478 & -0.936033991 & $7.62 \mathrm{E}-05$ \\
\hline ENSDARG00000045834 & -0.921661494 & 1.63E-07 \\
\hline ENSDARG00000024503 & -0.881635247 & 4.24E- 05 \\
\hline ENSDARG00000056765 & -0.850236732 & $3.16 \mathrm{E}-08$ \\
\hline ENSDARG00000033854 & -0.847319022 & 0.00021264 \\
\hline ENSDARG00000039393 & -0.83487661 & $8.09 \mathrm{E}-05$ \\
\hline ENSDARG00000041569 & -0.805620387 & 0.0002295 \\
\hline ENSDARG00000029587 & -0.798510485 & 0.00018023 \\
\hline ENSDARG00000018263 & -0.789477991 & $8.43 \mathrm{E}-05$ \\
\hline ENSDARG00000086254 & -0.775585332 & 0.00013736 \\
\hline ENSDARG00000009153 & -0.77272349 & $1.86 \mathrm{E}-07$ \\
\hline ENSDARG00000030616 & -0.771999685 & $2.35 \mathrm{E}-05$ \\
\hline ENSDARG00000030915 & -0.769078697 & $4.08 \mathrm{E}-05$ \\
\hline ENSDARG00000042993 & -0.759414196 & $2.85 \mathrm{E}-05$ \\
\hline ENSDARG00000077058 & -0.748679878 & 0.00021958 \\
\hline ENSDARG00000002396 & -0.737186432 & $9.06 \mathrm{E}-05$ \\
\hline ENSDARG00000007276 & -0.731121935 & $1.76 \mathrm{E}-05$ \\
\hline ENSDARG00000015123 & -0.727327583 & 0.00012357 \\
\hline ENSDARG00000102442 & -0.719815554 & 4.27E-05 \\
\hline ENSDARG00000105411 & -0.707858646 & 0.00013593 \\
\hline ENSDARG00000057437 & -0.684000585 & $7.08 \mathrm{E}-05$ \\
\hline ENSDARG00000090428 & -0.68164618 & 3.10E-05 \\
\hline ENSDARG 00000103687 & -0.66146725 & $1.01 \mathrm{E}-05$ \\
\hline ENSDARG00000068680 & -0.66001916 & $9.90 \mathrm{E}-05$ \\
\hline ENSDARG00000020123 & -0.648795043 & $2.42 \mathrm{E}-05$ \\
\hline ENSDARG00000039730 & -0.63234854 & 0.0001393 \\
\hline ENSDARG00000076011 & -0.630164232 & 0.00022674 \\
\hline ENSDARG00000033832 & -0.625143351 & 4.76E-05 \\
\hline ENSDARG00000009443 & -0.621954227 & $2.05 \mathrm{E}-05$ \\
\hline ENSDARG00000040432 & -0.604641591 & $8.15 \mathrm{E}-06$ \\
\hline ENSDARG00000053097 & -0.55692281 & 0.00019994 \\
\hline ENSDARG00000088711 & -0.54155565 & 0.0001904 \\
\hline ENSDARG00000101160 & -0.521525439 & $8.97 \mathrm{E}-05$ \\
\hline ENSDARG00000053358 & 0.506539149 & $4.31 \mathrm{E}-05$ \\
\hline ENSDARG00000030614 & 0.53052294 & $7.36 \mathrm{E}-05$ \\
\hline ENSDARG00000099203 & 0.562147944 & $8.42 \mathrm{E}-06$ \\
\hline ENSDARG00000055216 & 0.567916067 & 0.00011944 \\
\hline ENSDARG00000020795 & 0.583776186 & 0.00015794 \\
\hline ENSDARG00000007654 & 0.601581979 & 0.00021243 \\
\hline ENSDARG00000039647 & 0.607944755 & 0.00017374 \\
\hline ENSDARG00000027419 & 0.612777357 & $7.48 \mathrm{E}-05$ \\
\hline ENSDARG00000025106 & 0.619971087 & 0.00023034 \\
\hline ENSDARG00000076364 & 0.628462284 & 0.00016385 \\
\hline ENSDARG00000103937 & 0.648166679 & $1.66 \mathrm{E}-05$ \\
\hline ENSDARG00000022995 & 0.652667549 & $3.41 \mathrm{E}-05$ \\
\hline ENSDARG00000099257 & 0.654101819 & 0.00018766 \\
\hline ENSDARG00000102453 & 0.658745469 & $2.80 \mathrm{E}-05$ \\
\hline ENSDARG00000059775 & 0.670043489 & $1.67 \mathrm{E}-05$ \\
\hline ENSDARG00000017673 & 0.671384509 & $6.75 \mathrm{E}-05$ \\
\hline ENSDARG00000086222 & 0.675190414 & $3.75 E-05$ \\
\hline ENSDARG00000100166 & 0.694355451 & 0.00024185 \\
\hline ENSDARG00000059945 & 0.766331798 & $1.13 \mathrm{E}-06$ \\
\hline ENSDARG00000068745 & 0.771799195 & 0.00013402 \\
\hline ENSDARG00000051970 & 0.816336471 & 0.00014345 \\
\hline ENSDARG00000114797 & 0.852062415 & $9.73 \mathrm{E}-05$ \\
\hline ENSDARG00000000503 & 0.860377519 & $1.66 \mathrm{E}-06$ \\
\hline ENSDARG00000015537 & 0.886970984 & 1.40E-05 \\
\hline ENSDARG00000097196 & 0.900381828 & $2.74 \mathrm{E}-06$ \\
\hline ENSDARG00000105201 & 0.949578108 & $1.57 \mathrm{E}-06$ \\
\hline ENSDARG00000040123 & 0.97270037 & 0.00021835 \\
\hline ENSDARG00000098880 & 1.000025811 & 7.19E-06 \\
\hline ENSDARG00000030376 & 1.024003877 & $1.86 \mathrm{E}-05$ \\
\hline ENSDARG00000057660 & 1.02770991 & $3.94 \mathrm{E}-05$ \\
\hline ENSDARG00000012610 & 1.085030009 & $6.02 \mathrm{E}-06$ \\
\hline ENSDARG00000053205 & 1.147549538 & $2.21 \mathrm{E}-05$ \\
\hline ENSDARG00000079997 & 1.401524233 & 0.00010231 \\
\hline ENSDARG 00000100339 & 1.515219022 & 0.00010157 \\
\hline ENSDARG00000079078 & 6.289376582 & $4.81 \mathrm{E}-05$ \\
\hline ENSDARG00000097011 & 6.667965594 & 6.44E-05 \\
\hline Extra genes 4 -fold up bu & ut not padj & \\
\hline ENSDARG00000097238 & 7.203654746 & NA \\
\hline ENSDARG00000089087 & 7.317595408 & 0.00204913 \\
\hline ENSDARG00000059039 & 7.407254142 & 0.05813054 \\
\hline
\end{tabular}


bioRxiv preprint doi: https://doi.org/10.1101/2020.12.09.416727; this version posted December 9, 2020. The copyright holder for this preprint (which was not certified by peer review) is the author/funder, who has granted bioRxiv a license to display the preprint in perpetuity. It is made

Table S2: Read counts mapping to four haemoglobin genes located on a small region of chromosome 3. * genes are not significantly differentially expressed but show strong expression in samples $\mathrm{H} 1$ and $\mathrm{H} 2$ who were the most resilient to loss of equilibrium in hypoxic environment. Note that there are two versions of hbba1 due to genome duplication, and they are physically separated on chromosome 3.

\begin{tabular}{llllllll}
\hline EnsembI ID & Gene name & C1 & C2 & C3 & H1 & H2 & H3 \\
\hline ENSDARG00000079078 & $h b z$ & 0 & 0 & 2 & 9 & 303 & 1 \\
ENSDARG00000097011 & $h b a a 1$ & 2 & 1 & 17 & 671 & 1427 & 14 \\
ENSDARG00000097238 & $h_{b b a 1^{*}}$ & 0 & 0 & 8 & 341 & 974 & 8 \\
ENSDARG00000089087 & hbba1 $^{*}$ & 1 & 3 & 13 & 227 & 1169 & 21 \\
\hline
\end{tabular}


bioRxiv preprint doi: https://doi org/10.1101/2020 12.09.416727; this version posted December 9,2020. The copyright holder for this preprint (which was not certified by peer review) is the author/funder, who has granted bioRxiv a license to display the preprint in perpetuity. It is made available under aCC-BY-NC-ND 4.0 International license.

Table S3. Whole genome bisulfite sequencing of the sperm of hypoxic vs. control males
The table lists the general sequencing statistics as well as the number of cytosine calls at either CG dinucleotides ('CG') or in other sequence contexts ('non-CG'), for the samples used in the experiments, mapped against the Zebrafish genome version 11 (GRCz11). 作

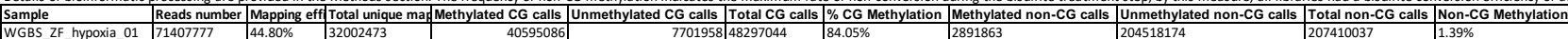

\begin{tabular}{|c|c|c|c|c|c|c|c|c|c|c|}
\hline NGBS ZF hypoxia 01 & 71407777 & $44.80 \%$ & [320024/3 & 40595086 & $7701958 \mid 48297044$ & $184.05 \%$ & 2891863 & |204518174 & 207410037 & $1.39 \%$ \\
\hline WGBS ZF hypoxia 02 & 63581861 & $44.90 \%$ & 28517341 & 37211081 & \begin{tabular}{|l|l}
6924223 & 44135304
\end{tabular} & $84.31 \%$ & 2802223 & 186459744 & 189261967 & $1.48 \%$ \\
\hline WGBS_ZF_hypoxia_03 & 74348252 & $44.90 \%$ & 33365526 & 41945900 & \begin{tabular}{|l|l|l|}
7945201 & 49891101 \\
\end{tabular} & $84.07 \%$ & 2933887 & 212658962 & 215592849 & $1.36 \%$ \\
\hline WGBS_ZF_control_01 & 60567819 & $45.10 \%$ & 27287633 & 34647909 & \begin{tabular}{|l|l|}
6480315 & 41128224 \\
\end{tabular} & $84.24 \%$ & 2529456 & 176922946 & 179452402 & $1.41 \%$ \\
\hline WGBS_ZF_control_02 & 62901530 & $45.20 \%$ & 28453313 & 35787583 & $\begin{array}{l}6746571 \\
42534154 \\
\end{array}$ & $84.14 \%$ & 2558652 & 183685718 & 186244370 & $1.37 \%$ \\
\hline WGBS_ZF_control_03 & 74540770 & $45.20 \%$ & 33692759 & 42528134 & \begin{tabular}{|l|l|l|}
7911181 & 50439315 \\
\end{tabular} & $84.32 \%$ & 3154853 & 216091870 & 219246723 & $1.44 \%$ \\
\hline
\end{tabular}

